\title{
COMPARATIVE VALUE OF RADIUM AND DEEP $\chi$ RAYS IN THE TREATMENT OF RETINOBLASTOMA*
}

BY

\author{
H. B. STALLARD \\ London
}

SHOULD retinoblastoma and neuro-epithelioma of the retina be treated by radium or by deep $x$ rays ? The statistics, observations, and comments in this paper are based on the following five series of patients, three of which were treated by radon seeds and radium, and two by deep $x$ rays.

(1) My own series of 32 patients treated by radon seeds and radium disks (1934-51).

(2) a. Foster Moore's series of five patients treated by radon seeds (1929-37).

$b$. Twenty-one patients treated by other surgeons in Great Britain, Canada, Australia, and the U.S.A.

(3) Christie Hospital and Holt Radium Institute, Manchester, series of eight patients treated by radium needles (1935-49).

(4) Reese's series of 53 patients treated by deep $x$ rays (1934-49).

(5) Windeyer's series of eleven patients treated by deep $x$ rays (1941-47).

\section{RADON SEEDS}

A number of ways of attaching radon seeds to the sclera have been devised. Foster Moore in 1929 was the first to use radon seeds; he inserted one interstitially into a retinoblastoma through a stab incision in the sclera, the length of which exactly corresponded to the circumference of the radon seed. The seed was securely tied to a rubber disk on the sclera at its site of entry.

This interstitial technique was abandoned in favour of suturing the radon seed to the surface of the sclera. A circumferential groove was made in the platinum envelope around the centre of the seed to accommodate a fine silk suture tied with a surgical knot and having a needle at each end for passage through the adjacent sclera. Foster Moore also tried spring clips around the waist of the radon seed with diverging teeth to engage in the sclera.

Joyce (1944) favoured tunnelling the sclera to retain the seed, and Johnston (1949) adopted a similar procedure in making a scleral pouch for its retention. It is not difficult to make a scleral bridge with two parallel incisions $3 \mathrm{~mm}$. apart through half the thickness of the sclera, which is then split between the incisions and is lifted to allow the seed to be passed beneath the bridge. The seed is thus held in a bridge of sclera.

Waldmann (1940) fixed the seeds with clips into grooves set in a silver plate fashioned to the curvature of the sclera.

*Received for publication November 28, 1951.

Second part of the William McKenzie Memorial Lecture, 1951. 
The use of radon seeds has the disadvantage that the seed rides at a tangent to the sclera, and this, together with the fact that it is elongated, effects an uneven irradiation which is most intense at the site of fixation and lessens where the straight seed is not in direct contact with the sclera.

\section{RADIUM - DisKS}

Since the end of 1948, because of the imperfections involved in the use of radon seeds, I have used circular radium disks moulded to fit the radius of curvature of the sclera exactly, in the belief that these provide a more even

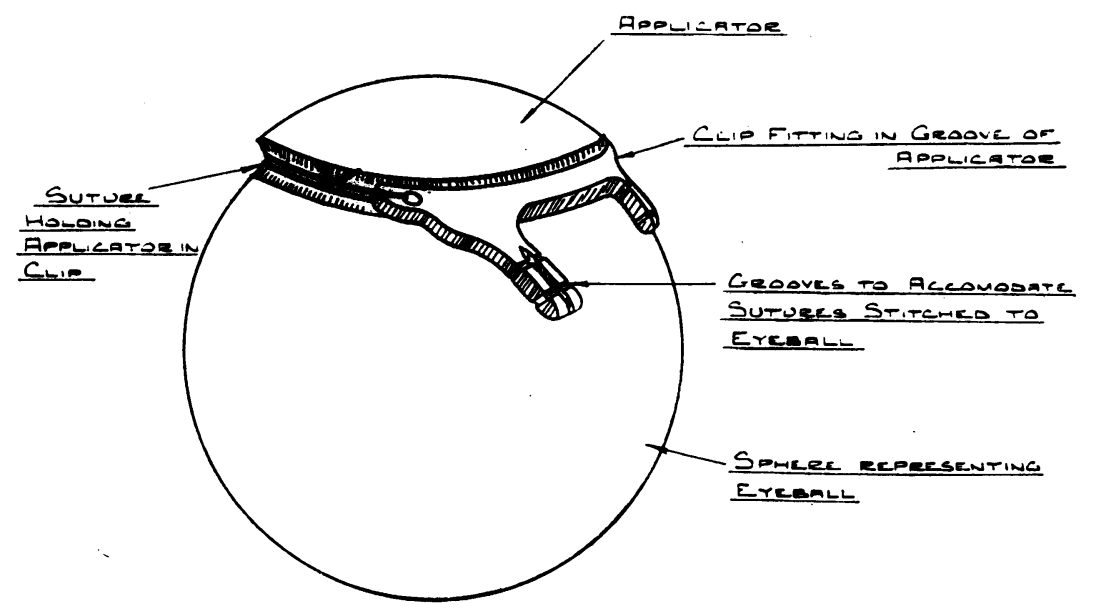

FIG. 1a.-Radium disk $5 \mathrm{~mm}$. diameter, with the clips and lugs for its retention (Stallard, 1948, Fig. 3).

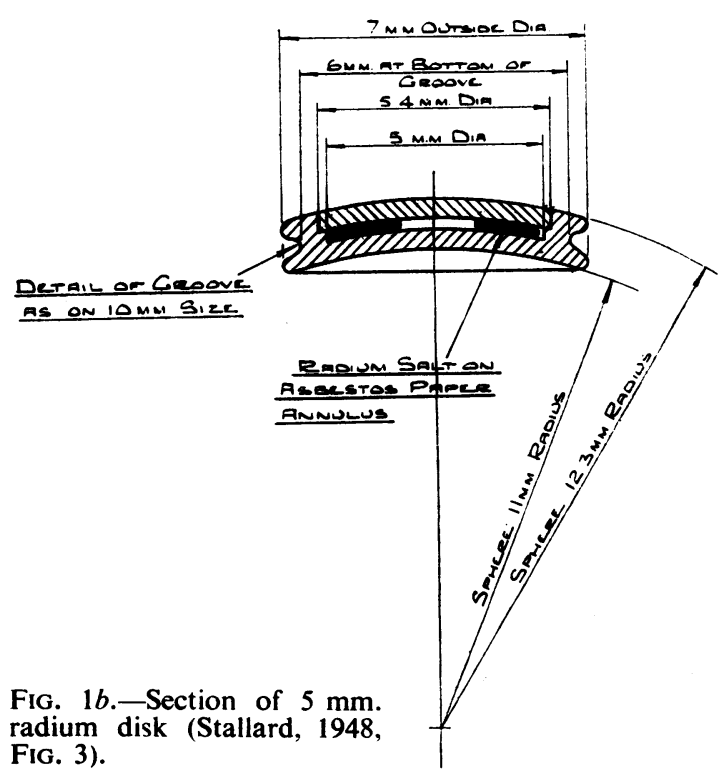

irradiation of the neoplasm than the cylindrical radon seeds.

These radium disks (Figs 1 and 2) have a platinum casing in the form of a segment of a spherical shell $1.3 \mathrm{~mm}$. thick, the inner radius of curvature being $11 \mathrm{~mm}$., the average for the scleral surface in a young child. The wall thickness of the platinum case is $0.5 \mathrm{~mm}$. and the depth of its cavity $0.3 \mathrm{~mm}$.

The edge of the disk is grooved around its entire circumference and it fits closely into the groove of a curved semi-circular clip, where it is 


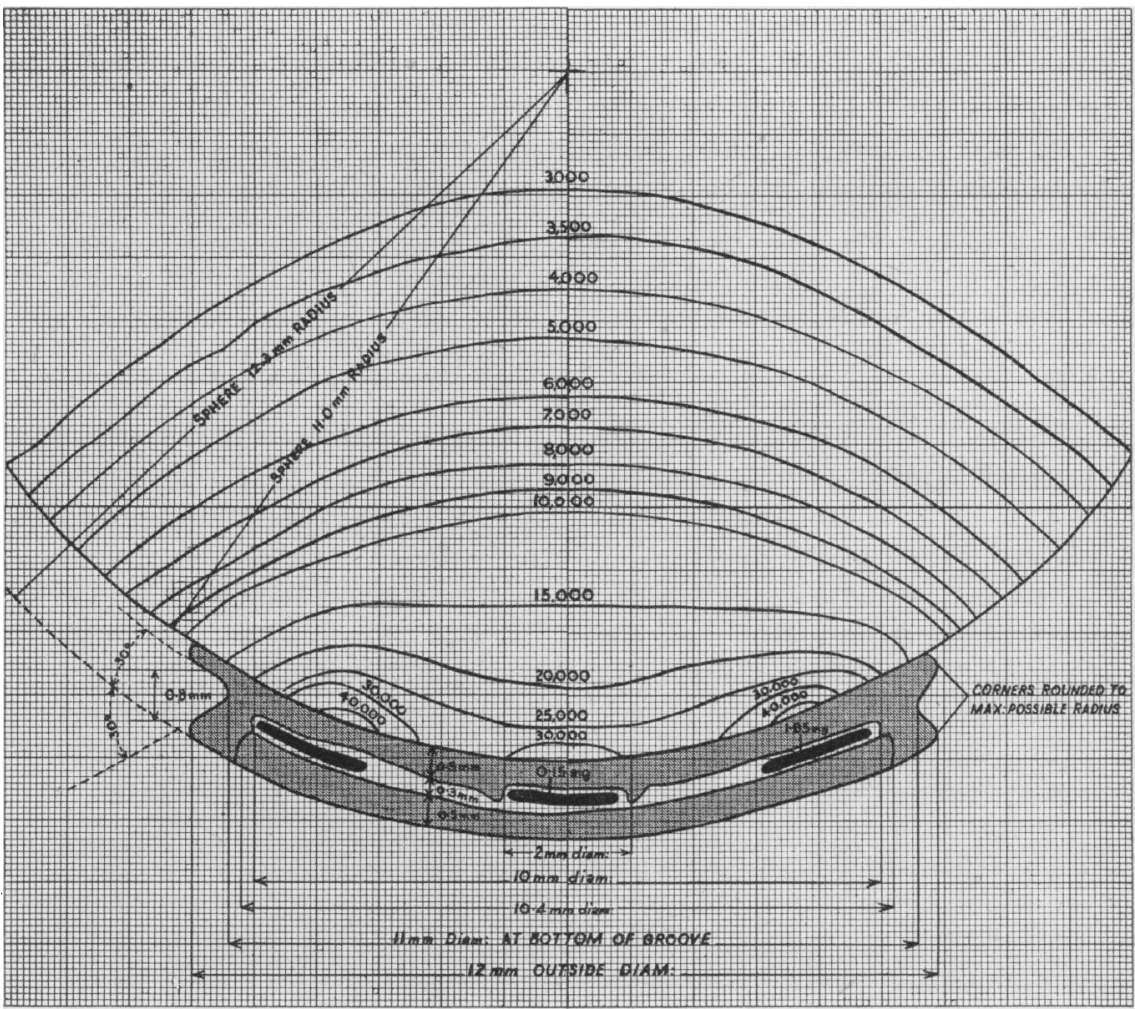

FIG. 2.-Dosage distribution from radium disk $10 \mathrm{~mm}$. diameter (Stallard, 1948, Fig. 4).

retained by a silk suture which passes through the holes at the ends of each lug and is thence drawn taut in the exposed groove round that part of the disk which is not in contact with the semi-circular clip. Two lugs, also curved like the disk, project from the clip; these are grooved transversely for the retention of the scleral sutures which secure the radium disk and its clip to the eye. The lugs may be of various lengths to facilitate attachment to the sclera by sutures. Within the cavity is a central circular disk surrounded after a short intervening gap by an annulus, both being made either of asbestos paper impregnated with radium salt, or of cobalt which has been placed in an intense beam of neutrons in the atomic pile at Harwell. Cobalt 59 captures a neutron to become Cobalt 60 , which is an unstable atom and disintegrates to nickel giving off gamma rays and beta particles. Since cobalt and nickel are toxic to tissues, the platinum envelope is sealed hermetically with silver solder. This distribution of either the radium or the irradiated cobalt is designed to make the dose as uniform as possible at the curved surface of the retina. Fig. 2 shows the distribution for a $10-\mathrm{mm}$. diameter radium disk. The $0.5-\mathrm{mm}$. thick platinum case absorbs alpha and beta radiation so that 
only gamma rays reach the tissues. Disks from 2 to $20 \mathrm{~mm}$. in diameter are used and their radium content ranges from 0.5 to $5 \mathrm{mg}$. The disks in more common use are $5 \mathrm{~mm}$. diameter with $1 \mathrm{mg}$. radium, and $10 \mathrm{~mm}$. diameter with $2.7 \mathrm{mg}$. radium. The radium loading has been calculated to give a dose of approximately 3,500 in one week $(168 \mathrm{hrs})$ at the apex of the neoplasm. For this purpose the height of the growth has been assumed to be $7 / 10$ of its diameter. The half life of an irradiated cobalt disk is 5.2 years, and in view of this decay rate the dose has to be adjusted at least once a year.

\section{Series 1}

Between 1934 and 1951 I have treated 32 patients, sixteen with radon seeds from 1934 to 1948, thirteen with radium disks from 1948 to 1951, and three by deep $x$ rays and then radium disks. In one case radium disks were applied to both eyes, so that the total number of eyes treated to date by this technique is seventeen.

All three patients who were given deep $x$ rays and then radium were prognostically unfavourable, for more than half the retina had already been destroyed by the neoplasm and the remainder was detached. The therapeutic intention in these advanced cases was to destroy as much of the growth as possible by deep $x$ rays, and then to deal with any remaining localized active residue with a radium disk in the vain hope that the perception of light which seemed to exist in the detached retina would give the child some measure of guiding vision. All these cases ultimately failed, necessitating excision of the eye $1 \frac{1}{2}-2$ years after treatment on account of intra-ocular complications. There was a severe vitreous haemorrhage and complicated glaucoma in two cases, and in the third there occurred endophthalmitis possibly excited by toxins from a mass of cells destroyed by irradiation. In two of these cases, however, there was no certain evidence on microscopic examination of serial sections that any active retinoblastoma cells remained.

Of the 29 patients ( 30 eyes) treated by radon seeds and radium disks, 24 have some useful vision, and there is no evidence of recurrence in the irradiated eye. Seven of these 24 patients are still alive more than 5 years after irradiation, the periods of survival being 17 years (one), 16 years (one), 15 years (one), 14 years (one), 13 years (two), and 5 years (one). The results are shown in Fig. 3, opposite.

Of the five failures, who are all blind but still alive, two have kept their remaining irradiated eye with no sign of recurrence (one for 14 years and the other for 12 years) since the application of radon seeds. In three cases the irradiated eye had been excised-because of total detachment in two and vitreous haemorrhage and complicated glaucoma in the third. Microscopic examinations of serial sections of these eyes showed no clear histological evidence of active retinoblastoma cells. Three patients who had the neoplasm in their remaining eye successfully treated (one by radon seeds and the other two by a radium disk) and had good vision with an unaffected macula and a healthy-looking optic disk, died from a recurrence in the orbit of the excised eye, the recurrence having been unsuccessfully treated by deep $x$ ray in each case. It is probable that the proper action to take in such cases is immediate exenteration followed by deep $x$-ray treatment. (In Reese's series an orbital recurrence was fatal in every case in which it occurred.) 
In the successfully irradiated eyes the visual acuity is now:

$6 / 6$ so far as can be judged by illiterate tests ... ten cases.

6/9 6/6 partly. (Edge of macula scarred.) $\ldots$ one case.

$6 / 24$ where the macula was involved in the growth one case.

with aphakia and perimacular exudates $\ldots$ one case.

$6 / 36$ where the macula was involved in the growth one case

$6 / 60$ with neoplasms situated at the macula $\ldots$ two cases-one also had

Perception of light $\ldots \quad \ldots \quad \ldots \quad \ldots \quad \ldots$ one case.

central lens opacities.

The remaining seven patients, one of whom had both eyes irradiated, are still too young for any reasonable estimate of their vision to be made. One is aphakic and seems to have vision better than 6/60. It is remarkable that four patients with the scar of the successfully irradiated neoplasm obliterating the papillo-macular region have been able to use the nasal part of the retina to read. One boy reads J.4 and draws most accurately.

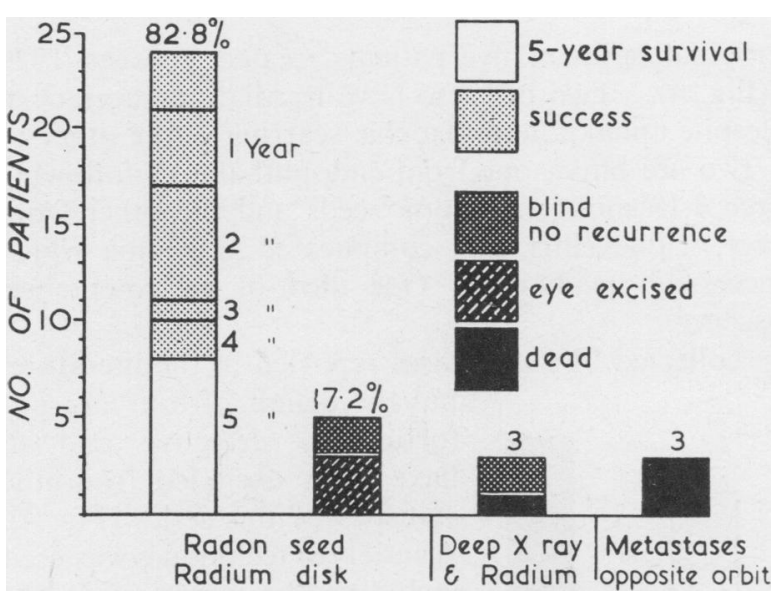

Fig. 3.-Results of Series 1. Numerals to the right of first column (successes) indicate survival time in years after irradiation.
Complications.-The reasons for the failures which resulted in loss of sight and excision of the irradiated eye have been given above as total retinal detachment, complicated glaucoma, and severe intra-ocular haemorrhage. Such complications occurred in eyes where more than half of the retina was destroyed by the neoplasm, and where three or more large islands of growth were near the optic disk. The complications in those cases classified as being successful with some preservation of vision were as follows:

(1) Cataract necessitated the extraction of the lens in three cases. A small opacity about $1.5 \mathrm{~mm}$. in diameter has remained stationary in the centre of the posterior cortex in three cases and at the equator in the upper nasal quadrant in one case.

In six cases the opacity followed the use of radon seeds and in one, where a $1.0 \mathrm{mg}$. radium disk was applied between the equator and ora serrata, a small posterior cortical opacity has appeared. It is probably still too early to judge whether the incidence of irradiation cataract will be affected by the radium disk technique which $I$ have used only since the end of 1948 .

In five cases the opacity followed the application of three or four 2 millicurie radon seeds, and in one case it occurred after the use of one 2 millicurie seed placed between the equator and the macula.

In the three cases in which the lens became so opaque that discission and curette evacuation were necessary, the radon seeds had been placed just behind the equator; in two in which there was a small central posterior cortical opacity, the seeds had been sutured to the sclera over the macula. The earliest onset of lens opacification was 10 months after the application of a $1.0 \mathrm{mg}$. radium disk, and the longest 11 years and 6 months after three 1.1 millicurie radon seeds had been applied over the macula. 
(2) Retinal Exudates resembling circinate retinopathy were present at and around the macula in three patients who had radon seeds applied behind the equator. These exudates appeared from 7 months to 9 years after irradiation and have persisted for 11 years.

(3) Retinal Haemorrhages on a small scale occurred in three cases. In one these appeared 3 years and 1 month after irradiation of the macula and have persisted for 13 years; in another a small retinal haemorrhage occurred adjacent to the optic disk 1 year after the application of a 2 millicurie radon seed to the macula; in the third a haemorrhage over the irradiated papillomacular area appeared when the patient was 14 years old, 13 years after irradiation.

(4) White Sheathing of Larger Branches of Retinal Vessels around the optic disk and pallor of the disk occurred in two cases after the application of a radium disk behind the equator.

(5) Diffuse Choroidal and Subretinal Haemorrhage.-This occurred 7 months after the use of a $2.7 \mathrm{mg}$. radium disk to irradiate a large mass around the macula and optic disk. This haemorrhage absorbed in 3 months.

\section{Series 2}

(a) Foster Moore.-In the original series of five patients treated between 1929 and 1937 four have survived (Fig. 4). Two of these have irradiation cataract in one eye and sufficient vision despite aphakia and macular scarring in the other to enable them to earn a living; two are blind, one from endophthalmitis following the interstitial insertion of three 3.18 millicurie radon seeds and the other from severe intra-ocular haemorrhage, iridocyclitis, and complicated glaucoma which occurred 11 months after successful irradiation. One died of gastro-enteritis during post-operative convalescence.

(b) Other Surgeons.-I have collected 21 other cases reported in the literature,

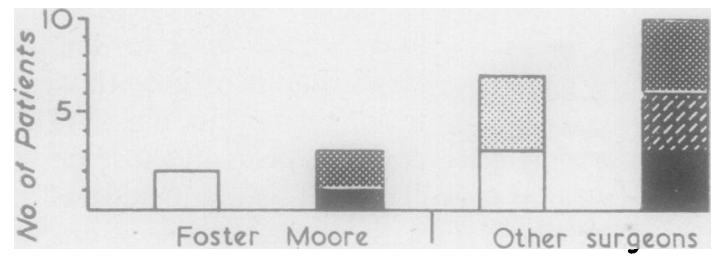

FIG. 4.-Comparative results of Foster Moore and other surgeons (Series $2 a$ and $b$ ).

plaques containing radium needles. It is clearly pident that the insertion radium needles into the orbit damaged the eye so consid the insertion of was lost, and that the results of using Columb needles were quite disastrous in every columbia paste plaques holding radium (he distrous in every case, since they failed to destron small islands of retinoblastoma. Of the four patients treated by this Columbia paste plaque technique, two died of metastases and two were blinded by dense vascularized opacification of the cornea. One child also suffered distortion of the upper, lid and trichiasis. Two patients who had radium needles inserted around the eye both lost the irradiated eye from complicated glaucoma. The tragedy is that in all six. of these cases the islands of neoplasm were small and should have responded to treatment by either a radon seed or a radium disk fixed to the sclera at the appropriate site.

A radio-active tantalum wire doubled to form a rectangular frame was used in 
one case but there is so far no evidence that the patient has perception of light. This case was complicated by iritis, irradiation cataract, and retinal detachment.

In these as in Foster Moore's series all the successes were obtained by radon seeds (Fig. 4). Of the seven successes, three are still alive 5 years after treatment and the vision is from $6 / 6$ to $5 / 60$.

Of the other four failures, one died from metastases, two became blind from total retinal detachment, and one received too much irradiation for the eye to retain any useful function.

\section{Series 3}

At the Christie Hospital and Holt Radium Institute, Manchester, from 1935 to 1949 , the remaining eye of six patients and both eyes of two patients suffering from retinoblastoma were treated by the insertion of radium needles through the skin of the eyelids posteriorly into the orbit. Here the points converged to make a truncated cone with its anterior diameter about $3 \mathrm{~cm}$. and its sides $1.5-4.5 \mathrm{~cm}$. long depending on the active length of the needles. In some cases four needles were also disposed as a coronal frame in the orbit about the plane of the equator of the eyeball (Figs 5 and 6). This distribution of the needles was made regardless of the site of the retinoblastoma, which in four instances occupied less than one quadrant of the eye and in another case was at the papillomacular area and measured $6 \times 4.5 \mathrm{~mm}$. The needles were left in place for 7 days in most cases, the least time being 4 days and the greatest 9 days.
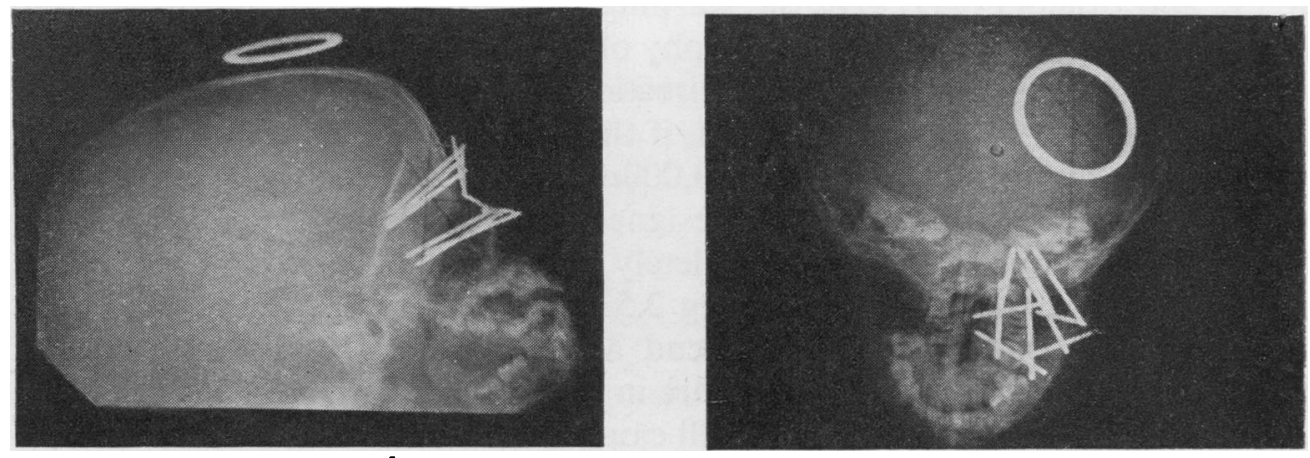

FIGS 5 and 6.-Arrangement of radium needles.

The following table shows the loading and radio-active lengths of the needles.

\begin{tabular}{|c|c|c|}
\hline $\begin{array}{c}\text { Radium } \\
\text { Loading } \\
\text { (mg.) }\end{array}$ & \multicolumn{2}{c|}{ Length } \\
\hline 2 & $\begin{array}{c}\text { Active } \\
\text { (cm.) }\end{array}$ & $\begin{array}{c}\text { Total } \\
\text { (cm.) }\end{array}$ \\
\hline 1 & 3 & 4.5 \\
\hline 1 & 1.5 & 2.7 \\
\hline 0.5 & 2.0 & 3.5 \\
\hline $\begin{array}{l}1.33 \\
0.66\end{array}$ & & \\
\hline 0.33 & & 2.0 \\
\hline
\end{tabular}

A trial was made of loading needles 2.5 and $3 \mathrm{~cm}$. long with radon seeds of $5 \mathrm{~mm}$. active length and 0.37-2.3 millicuries strength, placed in the hollow shaft near the tip of the needle. The dose used for these eight patients varied from $5,000-7,000 r$, and four of them also had deep $x$-ray treatment directed at the apex of the orbit, $367-1,550$ r being given on one day after the removal of the needles. Fig. 7 (p. 321) shows the results. 
Three children have some vision, one of these at the age of 4 is reported as having sufficient sight to guide her blind parents about their house; the other two have eccentric vision, for in one the macula was destroyed by the neoplasm and in the other it was probably damaged by irradiation. This latter patient attends a special school.

Of the five failures, one is blind in both eyes which he has retained, three have had their blinded eyes removed (one of these had both eyes irradiated and subsequently excised), and one whose eye was reported to be full of retinoblastoma died after an orbital recurrence.

The causes of failure in five eyes have been severe intra-ocular haemorrhage and retinal detachment, and in another patient it is likely that behind the irradiation cataract in both eyes there is gross destruction of the retina for there is no perception of light in either eye. In four of these cases the neoplasm was small enough and was so situated that the visual prognosis should have been good with appropriate irradiation applied to the base of the neoplasm.

\section{DEEP $X$-RAY THERAPY}

There are appreciable technical difficulties in firing a narrow pencil of $x$ rays accurately on to the retina of a conscious infant with avoidance of the anterior segment of the eye for as many as 28 treatments of 7 to 8 minutes' duration twice a week for $3 \frac{1}{2}$ months which are necessary in some cases. Reese and others (1949) give the warning that vision will be inevitably lost from cataract, iridocyclitis, and atrophy of the globe if a small fraction of the $x$-ray dose is given without proper direction of the beam and thus strikes the anterior segment of the eye. In fact, if the rays are fired directly through an anterior portal in doses of 2,000 to 3,000r, cataract and atrophy of the globe invariably follow. Special cones designed to prevent the scatter of rays to the anterior segment are not completely successful. Those used by Reese are circular, the temporal cone being 2.5 and the nasal $2.0 \mathrm{~cm}$. in diameter. Reese and his co-workers recommend a total dose of 8,000r, 400r being given at each treatment. Lack of care in aiming the beam which results in a deviation of as little as 1 to $2 \mathrm{~mm}$. will cause cataract. It is difficult to ensure the absolute immobility of a child's head held manually, and it seems that the margin of safety is even less when using the nasal portal. Indeed Reese himself has commented that the great disadvantage of $x$-ray treatment is the very prolonged course, which is really quite an ordeal not only for the child but for all concerned.

\section{Series 4}

In Reese's series of 53, the skin became depigmented, lost substance, was scarred, and showed telangiectases in every case. In eight of the 53, the bone growth of the nasal bridge became arrested leaving the child with a saddle-nose, and the results of correction by plastic operations were sometimes worse than the original deformity. Hollowing of the temporal fossa also occurred through interference with bone development. Post-irradiation sarcoma in the temporalis muscle and bones of the face occurred in four patients 7 or more years after treatment. Intraocular haemorrhages came on 5 to 21 months after the end of treatment in nineteen 


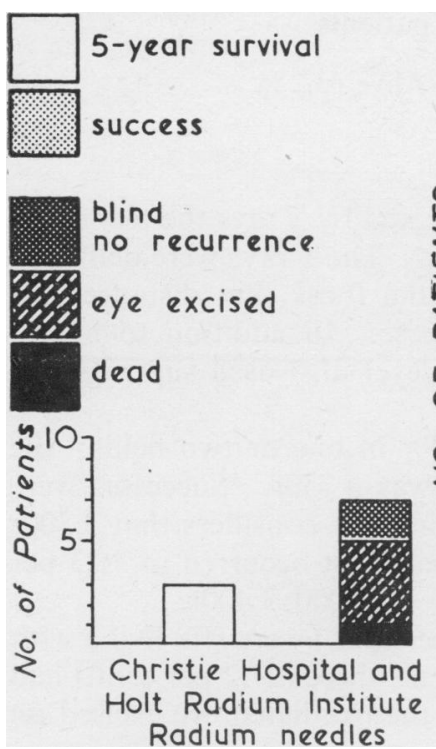

FIG. 7.-Results of use of radium needles (Series 3).

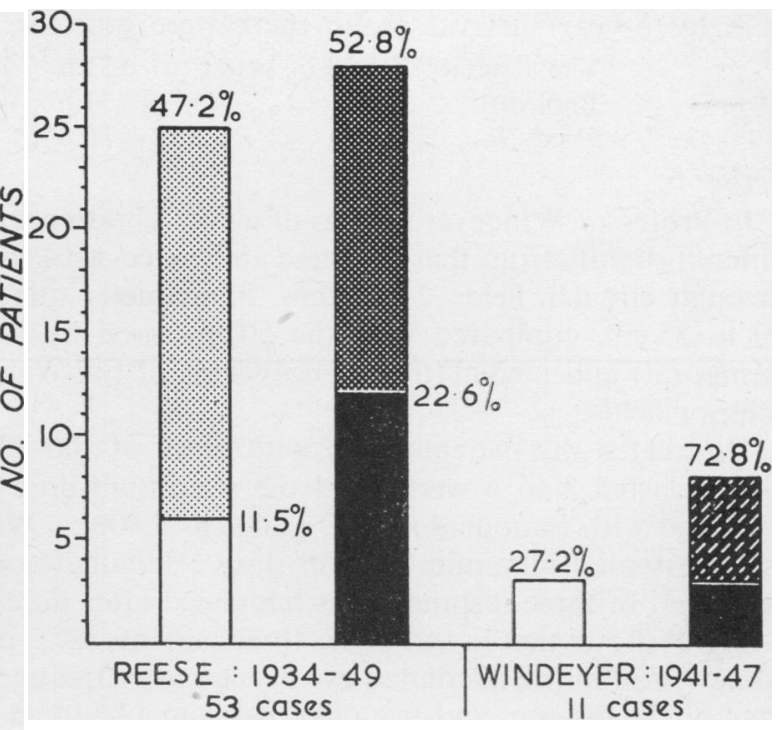

Fig. 8.-Results of deep $x$-ray therapy (Series 4 and 5).

(34.5 per cent.) of Reese's cases, two of these becoming atrophic and three being removed. In eight the haemorrhages recurred and in five they were absorbed. Epistaxis from intra-nasal telangiectases occurred in nine patients, and glaucoma occurred in nine (16.9 per cent.), its onset being on an average 1 year and 10 months after the beginning of treatment. Two patients responded to anti-glaucomatous treatment, and seven ended by excision of the globe.

The favourable and unfavourable conditions are much the same as in treatment of retinoblastoma by radon seeds or radium disks. A small flat neoplasm occupying less than one quadrant of the globe has a good prognosis. Detached fragments of the neoplasm in the vitreous and infiltration of the choroid generally signify a poor prognosis on account of wide intra-ocular dissemination.

There were occasionally good results when half the globe was involved, but such may be due to the radio-sensitivity of the neoplasm being greater than usual. Infiltration of the choroid was not controllable by $x$ rays.

The signs of regression after radio-therapy are diminution in the size of the neoplasm, increased sharpness of its margin, and the presence of dense white chalky areas. In rare instances the neoplasm disappears completely leaving little or no ophthalmoscopic trace of its site. Late sequelae are oedema and multiple discrete exudates at and around the fovea and macula.

In nineteen ( 34.5 per cent.) of Reese's cases the eye became atrophic and shrank. His results suggest that if there is no regression of the retinoblastoma after the maximum total dose of $8,000 \mathrm{r} \times 2$ in air, then further irradiation will cause blindness and serve no useful purpose, and in such cases he advises excision of the eye.

The results in Reese's series of 53 patients are shown in Fig. 8.

Visual acuity $20 / 200$ or better ... $47.2 \%$

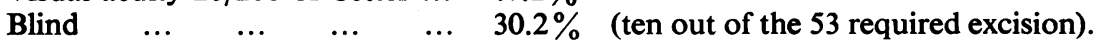

Died $\quad \ldots \quad \ldots \quad \ldots \quad \ldots \quad \ldots \quad 22.6 \%$ 
In his 5-year survival group there were nineteen patients:

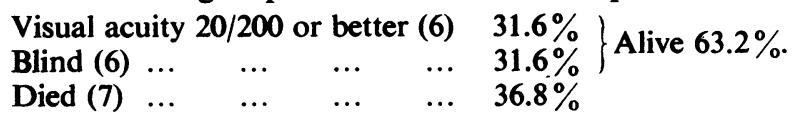

\section{Series 5}

Died (7) $\quad \ldots \quad \ldots \quad \ldots \quad \ldots \quad 36.8 \%$

In Professor Windeyer's series of eleven children treated by $x$ rays the technique differed slightly from that of Reese and his co-workers. The $x$ rays were delivered through circular fields 2 to $3 \mathrm{~cm}$. in diameter and the focal skin distance was 30 to $35 \mathrm{~cm}$. compared with the $50 \mathrm{~cm}$. used by Reese. In addition to lateral (temporal) and medial (trans-nasal) fields of fire Windeyer also used superior and inferior fields.

He treated the patients daily with doses of $100-300 \mathrm{r}$ in one or two fields; the course lasted 3 to 6 weeks and the maximum dose was 4,750r. Successes were obtained with tumour doses of $3,300 \mathrm{r}$ to $4,400 \mathrm{r}$. Windeyer considers that $3,300 \mathrm{r}$ is the essential miminum tumour dose. Irradiation cataract occurred in 36.3 per cent. and in three instances this happened after doses of 3,000-3,400r.

Fig. 8 shows that in this series three patients ( 27.2 per cent.) were still living with some vision in the irradiated eye 5 years after treatment, three (27.2 per cent.) had died of the disease, and five (45.6 per cent.) had had the irradiated eye excised on account of failure to arrest the neoplasm.

Four ( 36.3 per cent.) developed irradiation cataract; two of these recovered some useful vision after removal of the cataract, but the other two required excision of the eye on account of recurrence of the neoplasm, detachment of the retina, and iridocyclitis. Retinal detachment was a complication in three (27.2 per cent.), and retinal exudates and iritis were present in one case each.

Thus in Windeyer's series the successes were 27.2 per cent. and the failures 72.8 per cent. ( 27.2 per cent. dead and 45.6 per cent. living but blind).

\section{FoLLOW-UP}

Whilst small neoplasms under $5 \mathrm{~mm}$. in diameter may. disappear within 3 or 4 weeks after irradiation, with larger growths, when one quadrant or more has been affected, it is generally necessary to wait at least 2 months before it is possible to assess the maximum effect of irradiation.

Thereafter the patient is examined at monthly intervals until the age of 5 years to note the appearance of the irradiated site and to search for any islands of retinoblastoma which may have arisen spontaneously elsewhere in the fundus; particular care is taken to search the periphery of the fundus where a small hemispherical island $1 \mathrm{~mm}$. or so in diameter may appear.

After 5 years of age recurrences are very rare.

\section{CONCLUSIONS}

A study of these five series of cases has made it clearly evident that when one-third or less of the retina is involved in a retinoblastoma there is reasonable hope that the neoplasm may be destroyed by irradiation. With very few exceptions the results are bad when one half or more of the retina is already destroyed. Retinal detachment is generally present in such cases, and if it is not already present will almost certainly occur after irradiation. Later 
sequelae are severe intra-ocular haemorrhage, iridocyclitis, complicated glaucoma, and endophthalmitis. Irradiation often fails when the choroid is infiltrated. It would therefore seem advisable in such advanced cases to excise the eye with $10 \mathrm{~mm}$. of the optic nerve and to give post-operative irradiation of the orbit. In no instance in this series was the irradiation of such an eye worth while.

The dose is still empirical. It is a fact that the neoplasm in some patients is more radio-sensitive than in others, and I think it is evident that the retinoblastoma is more radio-sensitive than the more highly differentiated neuroepithelioma. It seems that a dose of 2,500-3,500 r at the summit of the neoplasm and up to $6,000-8,000 \mathrm{r}$ at its base is generally effective.

In my opinion it is desirable to bring the therapeutic artillery as close as possible to the target and to hit it hard and quickly with a concentration of fire that is known to be both effective and reasonably safe for the eye. To achieve this I think that radium disks made to fit the scleral curvature evenly are better than radon seeds and the other applicators so far used. This technique is preferable to long range shooting by heavy doses from radium needles fixed in Columbia paste plaques or from the radium 'bomb', for these methods are disastrous for the eye and are often ineffective in destroying the neoplasm. The results of different techniques are shown in Fig. 9.

Although deep $x$-ray treatment is successful in some cases, where less than one-third of the retina is affected by the neoplasm, it has the technical disadvantages of protracted treatment, and the difficulty of maintaining the

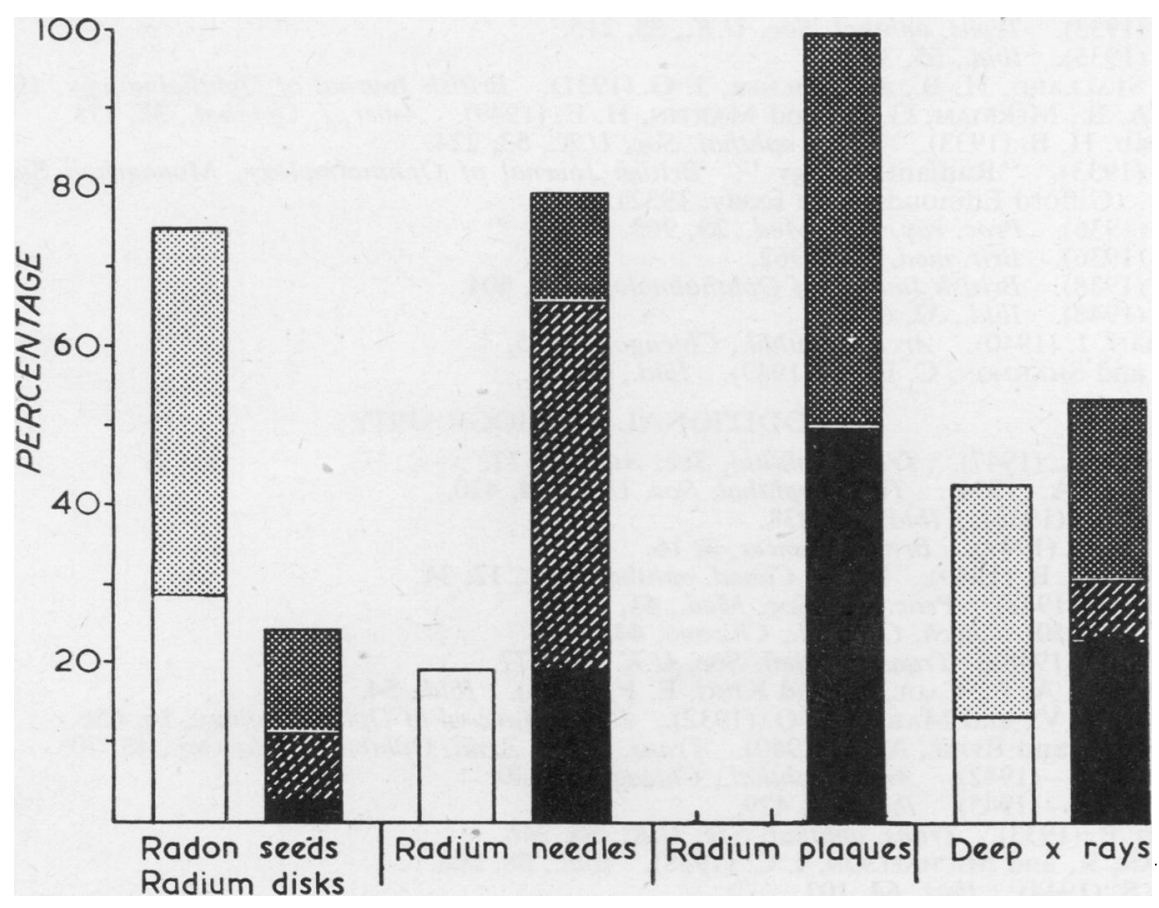

FiG. 9.-Comparison of results of different irradiation techniques in percentages. 
necessary immobility of a child's head, and it also produces a higher incidence of serious complications than follow the application of either a radium disk or a radon seed.

Fig. 9 demonstrates that the results of treatment by radon seeds and radium disks in several series in which the size of the retinoblastoma was fairly comparable are appreciably better than those of treatment by deep $x$ rays, radium plaques applied externally, and radium needles inserted into the orbital tissues around the eye.

The ethical problem of the preservation of tainted stock with potentiality to perpetuate this tragic disease is outside the scope of this work. It is hoped that those whom radio-therapy has enabled to survive with some useful measure of vision, or indeed without it, will at least have a eugenic conscience in this matter.

I am very grateful to Professor B. W. Windeyer of the Middlesex Hospital, and to Dr. Ralston Paterson, Dr. Dobbie, and Dr. Tod of the Christie Hospital and Holt Radium Institute, for their kindness in affording me facilities to examine their case records and pathological material and for their helpful advice. I thank Dr. Algernon B. Reese for his good counsels in private communications and for the mass of interesting information to be obtained from his papers on the treatment of retinoblastoma by deep $x$ rays. I am much indebted to my old chief Mr. Foster Moore with whom I was privileged to be associated in his pioneer work of treating retinoblastoma by radon seeds. I thank a number of colleagues who have been kind enough to send me their patients for radio-therapy.

Lastly I thank the William McKenzie Memorial Committee for their kindness in giving me permission to publish this lecture.

JOYCE, A. (1944). Trans. ophthal. Soc. Aust., 4, 98.

MOORE, R. Foster (1929). Proc. roy. Soc. Med., 22, 951.

L (1933). Ibid., 26, 1036.

(1933). Trans. ophthal. Soc. U.K., 53, 215.

(1935). Ibid., 55, 3.

Stallard, H. B., and Milner, J. G. (1931). British Journal of Ophthalmology, $15,673$.

Reese, A. B., Merriam, G. R., and Martin, H. E. (1949). Amer. J. Ophthal., 32, 175.

Stallard, H. B. (1933). Trans. ophthal. Soc. U.K., 53, 224.

(1933). "Radiant Energy". British Journal of Ophthalmology, Monograph Suppl. 6 (Gifford Edmonds Prize Essay, 1932).

(1936). Proc. roy. Soc. Med., 29, 963.

(1936). Brit. med. J., 2, 962.

(1938). British Journal of Ophthalmology, 22, 604.

(1948). Ibid., 32, 618.

Waldman, J. (1940). Arch. Ophthal., Chicago, 23, 55. and Shannon, C. E. G. (1949). Ibid., 41, 32.

\section{ADDITIONAL BIBLIOGRAPHY}

Gibson, W. L. (1947). Trans. ophthal. Soc. Aust., 7, 77.

GreEVES, R. A. (1934). Trans. ophthal. Soc. U.K., 54, 420.

GRIFFITH, A. (1933). Ibid., 53, 238.

JAPHA, E. M. (1949). Brit. J. Cancer, 3, 16.

JoHnston, K. B. (1949). Trans. Canad. ophthal. Soc., 12, 34.

KING, E. F. (1948). Proc. roy. Soc. Med., 41, 268.

LAVAL, J. (1950). Arch. Ophthal., Chicago, 44, 140.

LAW, F. W. (1948). Trans. ophthal. Soc. U.K., 68, 377.

MacCallan, A. F., CADE, S., and King, E. F. (1934). Ibid., 54, 201.

MCDOWALL, V., and MARKS, E. O. (1932). British Journal of Ophthalmology, 16, 686.

Martin, H., and Reese, A. B. (1940). Trans. Amer. Acad. Ophthal. Otolaryng., 45, 70. (1942). Arch. Ophthal., Chicago, 27, 40.

(1945). Ibid., 33, 429.

Martin, P. (1933). Trans. ophthal. Soc. U.K., 53, 246.

MeighaN, S., and Michaelson, I. C. (1938). Ibid., 58, 208.

Philps, S. (1944). Ibid., 64, 107. and Houlton, A. C. L. (1944). St. Bart's Hosp. J., 47, 278.

Ray, B. S., and McLean, J. M. (1943). Arch. Ophthal., Chicago, 30, 437.

SNELL, H. C. (1936). Trans. ophthal. Soc. U.K., 56, 269. 